\title{
Intimate Partner Violence Among Pregnant Veterans: Prevalence, Associated Mental Health Conditions, and Health Care Utilization
}

\author{
Suzannah K. Creech, Ph.D. ${ }^{1,2}$ (D), Carey S. Pulverman, Ph.D. ${ }^{1,2}$, \\ Aimee Kroll-Desrosiers, Ph.D., M.S. ${ }^{3,4}$, Rebecca Kinney, Ph.D. ${ }^{3}$, \\ Melissa E. Dichter, Ph.D., M.S.W. ${ }^{4,5}$, and Kristin Mattocks, Ph.D., M.P.H. ${ }^{3.6}$ \\ 'VHA VISN 17 Center of Excellence for Research on Returning War Veterans and the Central Texas Veterans Health Care System, Waco, USA; \\ ${ }^{2}$ Department of Psychiatry, Dell Medical School of the University of Texas at Austin, Austin, USA; ${ }^{3}$ VHA Central Western Massachusetts Healthcare

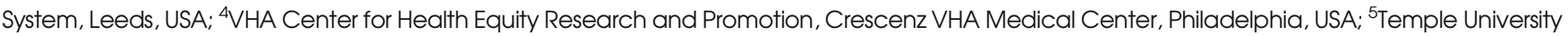 \\ School of Social Work, Philadelphia, USA; EUniversity of Massachusetts Medical School, Worcester, USA.
}

BACKGROUND: Intimate partner violence (IPV) is a prevalent and serious health concern for women veterans, associated with mental and physical health symptoms. The adverse impacts of IPV are exacerbated during pregnancy, with added risks for pregnancy and postpartum outcomes.

OBJECTIVE: Identify the scope of IPV among pregnant veterans and associations with health outcomes.

DESIGN: Data were obtained from a national retrospective cohort study.

PARTICIPANTS: Study participants were 442 pregnant veterans using VHA maternity care benefits.

MAIN MEASURES: Mental health history was assessed via self-report measure and chart review; history of IPV and perinatal depression were assessed via brief validated self-report measures.

KEY RESULTS: Fourteen percent of the sample reported past-year IPV. Report of past-year IPV was associated with higher self-reported rates of lifetime mental health disorders including depression ( $p=0.01)$, posttraumatic stress disorder $(p=0.02)$, anxiety disorders $(p=0.05)$, mood disorders $(p=0.01)$, bipolar disorder $(p=0.001)$, and eating disorders ( $p=0.003)$; past-year IPV was also

Suzannah K. Creech, Ph.D., VHA VISN 17 Center of Excellence for Research on Returning War Veterans and the Central Texas Veterans Health Care System, Waco, TX, and Dell Medical School of the University of Texas at Austin. Carey S. Pulverman, Ph.D., VHA VISN 17 Center of Excellence for Research on Returning War Veterans and the Central Texas Veterans Health Care System, Waco, TX, and Dell Medical School of the University of Texas at Austin. Aimee Kroll-Desrosiers, Ph.D., M.S., VHA Central Western Massachusetts Healthcare System, Leeds, MA, and Department of Population and Quantitative Health Sciences, University of Massachusetts Medical School, Worcester, MA. Rebecca Kinney, Ph.D., VHA Central Western Massachusetts Healthcare System, Leeds, MA. Melissa E. Dichter, Ph.D., M.S.W., Crescenz VHA Medical Center, Philadelphia, PA, and Temple University School of Social Work, Philadelphia, PA. Kristin Mattocks, Ph.D., M.P.H., VHA Central Western Massachusetts Healthcare System, Leeds, MA, and Department of Population and Quantitative Health Sciences, University of Massachusetts Medical School, Worcester, MA.

Prior Presentations N/A

Received August 11, 2020

Accepted December 17, 2020

Published online January 19, 2021 associated with the diagnosis of posttraumatic stress disorder during pregnancy $(p=0.002)$. Additionally, pastyear IPV was associated with higher rates of military sexual trauma (MST; $p=0.03$ ), pregnancy health risk behaviors (i.e., smoking, alcohol, and drug use; $p=0.004$ ), greater number of VHA mental health visits during pregnancy $(p=0.04)$, and a lower likelihood of seeking social support from a spouse or partner $(p<0.0001)$.

CONCLUSIONS: Results indicate substantial rates of IPV among pregnant veterans, and high rates of mental health conditions which may be exacerbated by MST experience and lower likelihood of seeking social support. Clinicians treating pregnant veterans should screen for and address IPV and mental health treatment needs, and risks should be assessed among pregnant veterans experiencing IPV.

KEY WORDS: women; veterans; intimate partner violence; pregnancy; perinatal depression.

J Gen Intern Med 36(10):2982-8

DOI: $10.1007 /$ s11606-020-06498-3

(C) This is a U.S. government work and not under copyright protection in the U.S.; foreign copyright protection may apply 2021

\section{INTRODUCTION}

Women veterans are a demographic group at high risk for intimate partner violence (IPV), which includes physical, sexual, and psychological abuse from a current or former intimate partner. Studies indicate that $18 \%$ of women veterans receiving Veterans Health Administration (VHA) care report pastyear IPV, and one-third of women veterans report lifetime IPV ${ }^{1-3}$ The number of women veterans using VHA maternity care benefits has been increasing rapidly; the number using benefits increased 14.4-times in a 15-period starting in FY2000. ${ }^{4}$ This increase underscores the need to examine the prevalence and correlates of IPV during pregnancy in this population. The negative health consequences of IPV are exacerbated during pregnancy, as women have increased physical, emotional, and financial needs, and IPV can impact maternal health and pregnancy outcomes. ${ }^{5,} 6$ These 
consequences may be heightened among women veterans who also experience elevated rates of lifetime sexual trauma (31\% childhood sexual trauma; $11 \%$ adulthood sexual trauma prior to military service), ${ }^{7}$ sexual assault or harassment during military service (military sexual trauma, MST; $38.4 \%^{8}$ ), and posttraumatic stress disorder (PTSD; $13.4 \%{ }^{9}$ ), all of which are associated with IPV experience and negative health outcomes. ${ }^{10}$ As IPV during the perinatal period conveys significant risk for adverse physical and mental health outcomes for women and the developing fetus, ${ }^{11,12}$ pregnant veterans may face particular health risks and needs. To our knowledge, no previous research has examined the impact of IPV during pregnancy on women veterans' health or treatment use.

In civilian populations, IPV during the perinatal period is associated with increased risk for depression, poor prenatal nutrition, substance abuse, adverse neonatal outcomes, and maternal and neonatal mortality. ${ }^{13,14}$ Thus, women experiencing IPV during pregnancy have an increased need for physical and mental health care; however, IPV is also associated with difficulties with treatment engagement and premature termination from treatment. ${ }^{13,15,16}$ Among women veterans, IPV is associated with increased use of VHA health care services such as emergency department utilization and inpatient stays, ${ }^{17}$ but poorer reported care continuity. ${ }^{3}$

Both women veterans and perinatal civilian women with recent IPV report increased need for and use of health care, but also greater difficulty obtaining that care. Pregnancy may be a time of particularly fractured care among women veterans using VHA health care. ${ }^{18}$ During the perinatal period, veterans receive prenatal and obstetric care outside of the VHA but may still receive other health care, such as primary or mental health care within the VHA. Primary care is the most widely used type of health care by women veterans at $\mathrm{VHA},{ }^{4}$ and in the community; ${ }^{19}$ thus, the impact of IPV on women veterans' health is relevant for all clinicians treating women veterans. Given the increased health risks of IPV and adverse outcomes during pregnancy, and particular considerations for veterans, it is important to understand the care needs of this population.

We examined the rates and correlates of IPV among a sample of pregnant veterans. Our objectives were to (1) identify the prevalence of past-year IPV among pregnant veterans using VHA care; (2) identify salient sociodemographic, military service, or social support characteristics among pregnant veterans screening positive for IPV; and (3) compare the rates of mental health, substance use, pain disorders, pregnancy health risk behaviors, and treatment use between pregnant veterans with and without past-year IPV. We hypothesized that pregnant veterans endorsing past-year IPV would report poorer mental health compared with their peers who did not report past-year IPV. We also hypothesized that there would be higher rates of pregnancy health risk behaviors and mental health treatment use among pregnant veterans reporting pastyear IPV compared to their peers who did not report past-year IPV.

\section{METHODS}

\section{Study Population}

Participants were enrolled in a larger cohort study, the Center for Maternal and Infant Outcomes and Research in Translation (COMFORT). Participants were women veterans utilizing VHA maternity care benefits recruited from 15 VHA medical centers across the USA between January 2016 and January 2020. Enrolled veterans participated in prenatal and postpartum interviews. This analysis uses data from the prenatal interview. Study methods have been described in greater detail elsewhere. ${ }^{18,20-23}$ The VHA Central Institutional Review Board approved this study and granted a waiver of written informed consent; however, verbal informed consent was obtained. Data available on request from authors.

Women from the COMFORT sample were eligible for this analysis if they had a complete prenatal interview (by $1 / 23$ / 20), completed an IPV screen, ${ }^{24}$ and could be matched by social security number to their VHA electronic medical record (EMR). All variables reported in this study were from the prenatal interviews (including self-report of mental health history and pregnancy health risk behaviors), except for mental health diagnoses, pregnancy health risk behavior diagnoses, and number of VHA mental health visits during pregnancy, which were obtained from the EMR.

\section{Classifying Intimate Partner Violence Exposure}

The E-HITS scale includes five items assessing IPV behaviors by a current or former partner in the past 12 months: physically hurt you, insulted you, threatened to harm you, screamed or cursed at you, forced you to have sexual activities. Responses are scored from 1-5, respectively: Never, Rarely, Sometimes, Often, Frequently. Total scores are the sum of all items. We dichotomized total scores into $<7$ and $7+$ based on previous work in women veterans. ${ }^{25}$

\section{Participant Characteristics}

Demographic data from the interviews included age, marital status, race, and ethnicity. Life situation was examined via employment status, current living situation (alone, with a partner, and/or children), housing situation (in house/ apartment one owns or rents, staying with family or friends). Military-related characteristics included service in Operations Enduring Freedom, Iraqi Freedom, and/or New Dawn (OEF/ OIF/OND); military branch; military service-connected disability, as determined by the veterans Benefits Administration; ${ }^{4}$ and military sexual trauma (MST). ${ }^{26}$

Medical history included both self-reported conditions and diagnoses obtained from ICD codes in the VHA EMR. We examined mental health conditions, substance use, and presence of musculoskeletal pain conditions during two time periods: in the 9 months prior to pregnancy, and during pregnancy. We created a composite "pregnancy health risk behaviors" variable that included self-reported smoking and/or an 
EMR diagnosis of alcohol use disorder, drug use disorder, or nicotine dependence during pregnancy. We also examined mental health care utilization during pregnancy, through the number of VHA mental health visits during pregnancy (as recorded in the EMR), as well as through self-reported responses to whether the participant planned to continue seeing a mental health provider during pregnancy.

Finally, we examined relevant pregnancy characteristics, including seeking social support from a spouse or partner, and prenatal depression symptoms as measured by the Edinburgh Postnatal Depression Scale (EPDS). The EPDS is a validated screening tool for pregnant women with a score of $\geq 10$ determined to be an optimal cut-off point for detecting depression symptoms during pregnancy. ${ }^{27} \mathrm{We}$ examined the EPDS by cut-off score $(<10, \geq 10)$.

\section{Data Analysis}

Descriptive analyses explored differences in participant characteristics by IPV exposure (E-HITS $<7$ vs. E-HITS 7+). We compared groups using chi-squared tests for categorical variables (with Fisher's exact tests when expected cell sizes were $<5$ ) and Student's $t$ tests for continuous variables, with Satterthwaite adjustment when appropriate. To further examine the association between participant characteristics and IPV exposure, we utilized logistic regression with backward selection, retaining significant variables from our bivariate analysis. To facilitate interpretation of our model, we dichotomized variables that were not initially dichotomized, including marital status (married vs. not), MST (any past MST vs. none), and any self-reported past mental health diagnosis (which included an affirmative response to any of the eight included mental health conditions). Odds ratios (ORs) and 95\% confidence intervals (95\% CIs) are reported. All analyses were conducted in SAS v.9.2 (SAS Institute, Inc., Cary, North Carolina).

\section{RESULTS}

Of our sample of 442 women veterans, 62 (14\%) scored a 7 or higher on the E-HITS, indicating past-year IPV. In the full sample, women were $32.4( \pm 4.5)$ years of age on average and $55.7 \%$ were white. In our sample, $52.5 \%$ of women reported being employed part or full-time. Most women (91.7\%) reported living in a home or apartment that they or their spouse owned or rented. The majority of our sample $(97.7 \%)$ served in OEF/OIF/OND; just under half (48.9\%) served most recently in the Army. Most of our sample (84.4\%) had a serviceconnected disability defined as health conditions linked to their military service. ${ }^{28}$ Demographic characteristics were similar between the IPV- and IPV+ groups, with the exception of marital status and living situation. Women in the IPV( $<7$ E-HITS) group were more likely to be married compared to women in the IPV+ (7+ E-HITS) group as well as report living with a spouse or partner (see Table 1). Significantly,
Table 1 Demographics and Military Characteristics by E-HITS Group $(N=442)$

\begin{tabular}{|c|c|c|c|}
\hline Characteristic & $\begin{array}{l}\text { E-HITS }< \\
7(n= \\
380)\end{array}$ & $\begin{array}{l}\text { E-HITS } \\
7+(n= \\
62)\end{array}$ & $p$ value \\
\hline Estimated age, $\mathrm{M} \pm \mathrm{SD}$, range & $\begin{array}{l}32.3 \pm 4.5 \\
(20.1- \\
44.6)\end{array}$ & $\begin{array}{l}32.8 \pm 4.8 \\
(22.4- \\
41.3)\end{array}$ & 0.40 \\
\hline \multicolumn{4}{|l|}{ Marital status $(n, \%)$} \\
\hline Single & $77(20.3)$ & $19(30.6)$ & \multirow{4}{*}{$\stackrel{<}{0.0001 *}$} \\
\hline Married & $268(70.5)$ & $24(38.7)$ & \\
\hline Divorced/separated/widowed & $34(8.9)$ & $19(30.6)$ & \\
\hline Missing/unknown & $1(0.3)$ & $0(0.0)$ & \\
\hline \multicolumn{4}{|l|}{ Race/ethnicity $(n, \%)$} \\
\hline White & $212(55.8)$ & $34(54.8)$ & 0.89 \\
\hline Black & $102(26.8)$ & $20(32.3)$ & 0.38 \\
\hline Other & $69(18.2)$ & $6(9.7)$ & 0.10 \\
\hline Hispanic or Latino/Latina & $81(21.3)$ & $8(12.9)$ & 0.15 \\
\hline $\mathrm{OEF} / \mathrm{OIF} / \mathrm{OND}(n, \%)$ & $372(97.9)$ & $60(96.8)$ & 0.64 \\
\hline $\begin{array}{l}\text { Employed part or full-time ( } n \text {, } \\
\% \text { ) }\end{array}$ & $198(52.1)$ & $34(54.8)$ & 0.73 \\
\hline \multicolumn{4}{|l|}{ Current living situation $(n, \%)$} \\
\hline With a spouse or partner & $327(86.1)$ & $36(58.1)$ & $\begin{array}{l}<.0001 * \\
0.00\end{array}$ \\
\hline $\begin{array}{l}\text { Children who are related to } \\
\text { you }\end{array}$ & $218(57.4)$ & $32(51.6)$ & 0.40 \\
\hline \multicolumn{4}{|c|}{ Housing situation in past six months $(n, \%)$} \\
\hline $\begin{array}{l}\text { Apartment or house that you } \\
\text { and/or your partner own }\end{array}$ & $190(50.0)$ & $27(43.6)$ & 0.35 \\
\hline $\begin{array}{l}\text { Apartment or house that you } \\
\text { and/or your partner rent or }\end{array}$ & $157(41.3)$ & $30(48.4)$ & 0.30 \\
\hline \multicolumn{4}{|l|}{ live in without paying rent } \\
\hline $\begin{array}{l}\text { Staying with family or a } \\
\text { friend }\end{array}$ & $29(7.6)$ & $3(4.8)$ & 0.60 \\
\hline Number of children in & $0.92 \pm$ & $0.90 \pm$ & \multirow[t]{2}{*}{0.87} \\
\hline \multicolumn{3}{|l|}{ Military branch $(n, \%)$} & \\
\hline Air Force & $78(20.5)$ & $6(9.7)$ & \multirow[t]{6}{*}{0.18} \\
\hline Army & $183(48.2)$ & $33(53.2)$ & \\
\hline Marine Corps & $39(10.3)$ & $10(16.1)$ & \\
\hline Navy & 75 (19.7) & $12(19.4)$ & \\
\hline Coast guard & $2(0.5)$ & $1(1.6)$ & \\
\hline Other & $3(0.8)$ & $0(0.0)$ & \\
\hline $\begin{array}{l}\text { Service-connected status ( } n \text {, } \\
\%)\end{array}$ & $319(83.9)$ & $54(87.1)$ & 0.64 \\
\hline $\begin{array}{l}\text { Seek social support from } \\
\text { spouse or partner during } \\
\text { pregnancy }(n, \%)\end{array}$ & $360(94.7)$ & $47(75.8)$ & $\begin{array}{l}< \\
0.0001 *\end{array}$ \\
\hline $\begin{array}{l}\text { MST harassment: Received } \\
\text { uninvited and unwanted } \\
\text { sexual attention during } \\
\text { military service }(n, \%)\end{array}$ & $190(50.0)$ & $40(64.5)$ & $0.03 *$ \\
\hline $\begin{array}{l}\text { MST rape: Force or the threat } \\
\text { of force was used to have } \\
\text { unwanted sexual contact } \\
\text { during military service }(n, \%)\end{array}$ & $111(29.2)$ & $27(43.5)$ & $0.03^{*}$ \\
\hline
\end{tabular}

Descriptive analyses examined differences in participant characteristics by women with IPV exposure (E-HITS $<7$ vs. E-HITS 7+). For categorical variables, we present the count and percentage; for continuous variables, means, standard deviation, and ranges are shown $* p<0.05$

more women in the IPV+ group reported a history of MST harassment or MST assault (see Table 2).

Women in the IPV+ group were significantly more likely to report or have indications of a pregnancy health risk behavior compared to women in the IPV- group $(17.7 \%$ vs. $6.1 \%, p=$ $0.004)$. Additionally, the IPV+ group had significantly higher proportions of women reporting a lifetime depression diagnosis, PTSD, anxiety, mood disorders, bipolar disorder, and eating disorders, compared to the IPV- group. Women in the 
Table 2 Health and Mental Health Conditions, Risk Behaviors, MST, and Mental Health Treatment by E-HITS Group

\begin{tabular}{|c|c|c|c|}
\hline Characteristic & $\begin{array}{l}\text { E-HITS < } \\
7(n=380)\end{array}$ & $\begin{array}{l}\text { E-HITS } \\
7+(n= \\
62)\end{array}$ & $\begin{array}{l}p \\
\text { value }\end{array}$ \\
\hline $\begin{array}{l}\text { Risky behaviors during } \\
\text { pregnancy } \dagger(n, \%)\end{array}$ & $23(6.1)$ & $11(17.7)$ & $0.004 *$ \\
\hline \multicolumn{4}{|c|}{ Self-reported past diagnoses $(n, \%)$} \\
\hline Depression & $220(57.9)$ & $47(75.8)$ & $0.01 *$ \\
\hline PTSD & 158 (41.6) & $36(58.1)$ & $0.02 *$ \\
\hline Anxiety disorder & $201(52.9)$ & $41(66.1)$ & $0.05 *$ \\
\hline Mood disorder & $27(7.1)$ & $11(17.7)$ & $0.01 *$ \\
\hline $\mathrm{ADHD}$ or $\mathrm{ADD}$ & $28(7.4)$ & $5(8.1)$ & 0.80 \\
\hline Bipolar disorder & $16(4.2)$ & $10(16.1)$ & $0.001 *$ \\
\hline Schizophrenia & $1(0.3)$ & $1(1.6)$ & 0.26 \\
\hline Eating disorder & $6(1.6)$ & $6(9.7)$ & $0.003 *$ \\
\hline \multicolumn{4}{|c|}{ EMR diagnoses 9 months prior to pregnancy $(n, \%)$} \\
\hline Hypertension & $14(3.7)$ & $2(3.2)$ & 0.99 \\
\hline Obesity & $39(10.3)$ & $6(9.7)$ & 0.99 \\
\hline TBI or head injury & $31(8.2)$ & $6(9.7)$ & 0.70 \\
\hline Pain non-cancer & $160(42.1)$ & $19(30.6)$ & 0.08 \\
\hline Sleep disturbance & $26(6.8)$ & $5(8.1)$ & 0.79 \\
\hline Major depressive disorder & $66(17.4)$ & $13(21.0)$ & 0.51 \\
\hline PTSD & $63(16.6)$ & $19(30.6)$ & $0.01 *$ \\
\hline $\begin{array}{l}\text { Schizophrenia or bipolar } \\
\text { disorder }\end{array}$ & $9(2.4)$ & $4(6.5)$ & 0.10 \\
\hline Anxiety & $45(11.8)$ & $14(22.6)$ & $0.03 *$ \\
\hline \multicolumn{4}{|c|}{ EMR diagnoses during pregnancy $(n, \%)$} \\
\hline Hypertension & $12(3.2)$ & $3(4.8)$ & 0.46 \\
\hline Obesity & 29 (7.6) & $5(8.1)$ & 0.99 \\
\hline TBI or head injury & $25(6.6)$ & $4(6.5)$ & 0.99 \\
\hline Pain non-cancer & $143(37.6)$ & $22(35.5)$ & 0.78 \\
\hline Sleep disturbance & $17(4.5)$ & $4(6.5)$ & 0.52 \\
\hline Major depressive disorder & $73(19.2)$ & $15(24.2)$ & 0.38 \\
\hline PTSD & $68(17.9)$ & $22(35.5)$ & $0.002 *$ \\
\hline $\begin{array}{l}\text { Schizophrenia or bipolar } \\
\text { disorder }\end{array}$ & $8(2.1)$ & $3(4.8)$ & 0.19 \\
\hline Anxiety & $41(10.8)$ & $5(8.1)$ & 0.49 \\
\hline $\mathrm{EPDS} \geq 10(n, \%)$ & $90(23.7)$ & $27(43.6)$ & $0.001 *$ \\
\hline \multicolumn{4}{|c|}{ Seeing a mental health provider prior to pregnancy $(n, \%)$} \\
\hline VHA Mental Health Provider & $133(35.0)$ & $25(40.3)$ & 0.42 \\
\hline $\begin{array}{l}\text { External Mental Health } \\
\text { Provider }\end{array}$ & $21(5.5)$ & $5(8.1)$ & 0.39 \\
\hline $\begin{array}{l}\text { Provider } \\
\text { Plans to continue seeing ANY }\end{array}$ & 123 & 28 & $0.05 *$ \\
\hline $\begin{array}{l}\text { mental health provider during } \\
\text { pregnancy }(n, \%)\end{array}$ & & & \\
\hline $\begin{array}{l}\text { \# of VHA mental health visits } \\
\text { during pregnancy }(\mathrm{M} \pm \mathrm{SD} \text {, } \\
\text { range) }\end{array}$ & $\begin{array}{l}2.6 \pm 5.3 \\
(0.0-34.0)\end{array}$ & $\begin{array}{l}5.3 \pm 9.6 \\
(0.0-54.0)\end{array}$ & $0.04 *$ \\
\hline $\begin{array}{l}\text { Ever counseling/treatment for } \\
\text { military sexual trauma }(n, \%)\end{array}$ & $96(25.3)$ & $20(32.3)$ & 0.25 \\
\hline
\end{tabular}

IPV+ group also had higher rates of PTSD and anxiety diagnoses recorded in the EMR in the 9 months prior to pregnancy. During pregnancy, the IPV+ group had higher proportions of women with an EMR diagnosis of PTSD. During pregnancy, women in the IPV+ group were significantly more likely to have an EPDS score $\geq 10$ compared to women in the IPVgroup $(43.6 \%$ vs. $23.7 \%, p=0.001$; Table 2$)$.

Results also revealed protective actions among pregnant veterans with past-year IPV. Mental health care utilization during pregnancy was higher among women in the IPV+ group. More women in the IPV+ group reported plans to continue seeing a VHA mental health provider during pregnancy; EMR data indicated that the number of VHA mental health care visits during pregnancy was indeed significantly higher in the IPV+ group compared to women in the IPVgroup (5.3 \pm 9.6 visits vs. $2.6 \pm 5.3$ visits, $p=0.04$; Table 2 ).

We included the following significant variables from our bivariate analysis in our multivariable regression model: marital status, seeking social support from a spouse or partner, pregnancy health risk behaviors, any past (self-reported) mental health diagnosis, any MST, EPDS score, and VHA mental health visits during pregnancy. While other variables were significant in bivariate analyses (e.g., current living situation; EMR diagnoses before or during pregnancy), we only included these specific variables to avoid collinearity. After backward selection, our logistic regression indicated that marital status, seeking social support, pregnancy health risk behavior, and prenatal EPDS were the strongest predictors of IPV exposure (E-HITS 7+ vs. E-HITS < 7). Women who were not married (OR 2.7; 95\% CI 1.5-5.0), those who did not report seeking social support from a spouse or partner (OR 3.6; $95 \%$ CI 1.6-8.2), who engaged in a pregnancy health risk behavior (OR 2.4; 95\% CI 1.0-5.6), or had an EPDS score $\geq 10$ (OR $2.0 ; 95 \%$ CI 1.1-3.7) were more likely than married women, women who sought partner or spousal social support, women who did not engage in a pregnancy health risk behavior, and women with an EPDS $<10$ to have IPV exposure, respectively (data not shown). Similarly, the number of women reporting seeking social support from a spouse or partner during pregnancy was significantly higher among those in the IPVversus IPV+ group $(94.7 \%$ vs. $75.8 \%, p<0.0001)$.

\section{DISCUSSION}

In this national study of pregnant women veterans using VHA health care, a substantial portion (14\%) experienced past-year IPV. Past-year IPV was associated with increased health concerns including depression, pregnancy health risk behaviors, and PTSD, warranting additional screening for these issues during the pre- and post-natal periods. That pregnant veterans who experienced IPV in the past year were also more likely to report history of MST, were less likely to be married, and less likely to report seeking support from a spouse or partner indicates potential additional needs such as alternative sources of social support during pregnancy. Taken together, these physical and mental health risks threaten the well-being of perinatal women veterans and their fetuses.

According to a 2019 VHA directive, ${ }^{29}$ VHA medical facilities are required to implement routine screening for IPV among all women veterans. Although the VHA screens all veterans for depression and PTSD annually, the current findings suggest that pregnancy should prompt a specific assessment of potential IPV-related needs and impacts given the increased health risks of IPV during pregnancy. For women veterans with positive IPV screens, the current findings suggest screening for depression, PTSD, and pregnancy health risk behaviors, each of which is associated with adverse health 
outcomes for the woman and developing fetus. Since pregnant veterans receive prenatal care outside VHA, it is also imperative that non-VHA providers are aware of the apparent heightened risk for IPV and consequences. Expanding education to community providers about the unique health care needs of women veterans, including the need for enhanced screening for IPV among pregnant veterans, may help to close this gap. This education could occur through conference trainings, publications, and VHA outreach.

Clinically, these results support efforts towards enhanced IPV prevention and intervention within VHA, and ensuring adequate support and advocacy services for pregnant veterans. Importantly, the majority of pregnant veterans in this sample were receiving VHA care before their pregnancies, giving VHA the opportunity address IPV-related concerns early. Pregnant veterans should be provided with information and support in connecting to pregnancy-related community resources, as well as resources on IPV prevention at the beginning of their pregnancies, to help facilitate access to advocacy and resources. For example, each VHA facility has an Intimate Partner Violence Assistance Program Coordinator who can help connect women to resources such as safety planning, shelters, crisis hotlines, advocacy, and counseling. Early provision of these resources could aid at-risk women in reducing their risk of IPV. Further supporting this notion, research in civilian samples has shown that brief IPV interventions delivered in primary care can improve safety planning, use of IPVspecific resources, and health outcomes. ${ }^{30}$

Pregnant veterans with a history of past-year IPV reported an average of 2.7 more VHA mental health care visits during pregnancy than pregnant veterans without a history of pastyear IPV, indicating that the VHA also provides ongoing care during pregnancy and suggests that VHA may be providing IPV-specific mental health services to those veterans. These results echo past studies which found that women veterans with histories of IPV report greater use of VHA health and mental health care than women veterans without histories of IPV,${ }^{17}$ yet this is the first time this has been reported specifically among pregnant veterans. Although many challenges to continuity of VHA care during pregnancy have been documented in the literature on pregnant veterans, ${ }^{18}$ it is encouraging that the high-risk group of pregnant veterans with pastyear IPV is making use of mental health care services available to them.

Findings are consistent with prior work showing associations between IPV and depression, PTSD, pregnancy health risk behaviors, and adverse health outcomes among women veterans; ${ }^{2,}{ }^{10}$ however, the health consequences may be particularly dire for pregnant veterans and their fetuses and could extend to lifetime morbidities for both. For example, both depression and PTSD during pregnancy have been associated with elevated rates of pre-term birth. ${ }^{31}$ Substance abuse during pregnancy frequently co-occurs with depression and PTSD, ${ }^{32}$, 33 and behaviors such as substance abuse have been associated with negative outcomes in infant growth, behavior, and cognition. ${ }^{34}$ In addition, psychopathology during pregnancy correlates highly with psychopathology in the postpartum period. ${ }^{35}$ Thus, women veterans experiencing IPV during pregnancy may be at high risk for mental health difficulties and substance abuse both during and after pregnancy. The extant literature shows these maternal difficulties convey risk of physical and mental health complications to the infant that cascade into adolescence ${ }^{36-38}$ and this may be compounded by IPV. Improving mental health and substance abuse treatment and reducing IPV re-victimization among this particularly vulnerable subpopulation of women veterans holds potential benefits for women veterans and their children. ${ }^{39,} 40$

The study included several limitations that warrant mention. Our sample included pregnant veterans using VHA maternity benefits who participated in the COMFORT study, which does not necessarily reflect the experiences of the larger population of veterans who use VHA maternity benefits, ${ }^{41}$ pregnant veterans who do not use VHA maternity benefits, or those who do not use any VHA care. The cross-sectional nature of the study inhibits our ability to draw causal connections between the variables. Concerns about stigma and social desirability may have led veterans to under-report their experiences of IPV, ${ }^{42}$ as is a methodological concern in all research on stigmatized life experiences. In addition, we did not assess the context in which IPV occurred, its severity, or impact. The EHITS measure assesses IPV in the past year; thus, we were unable to differentiate whether the IPV reported occurred prior to pregnancy, during pregnancy, or both.

In conclusion, IPV is a salient health risk for pregnant veterans with the potential to detrimentally affect maternal and fetal health. Future directions include studying the impacts of IPV on women veterans' birth outcomes, infant health, mother-infant bonding, and parenting, to better understand the long-term impact of IPV on women veterans' health. The current results also suggest opportunities for preventing IPV before it occurs. Pregnant veterans experiencing IPV reported seeking VHA mental health treatment at high rates, suggesting that this group is well-connected to VHA resources and thus may be able to receive additional support through VHA. Additional future directions include exploration of the unique factors that increase risk for IPV among reproductive-age women veterans, and best practices for the prevention of IPV victimization or re-victimization among this group. The potential to reduce the negative health impacts of IPV on both women and their children represents an incredible opportunity for VHA to intervene in the cycle of violence and morbidity that is often fueled by women's military experiences.

Corresponding Author: Suzannah K. Creech, Ph.D.; Department of Psychiatry, Dell Medical School of the University of Texas at Austin, Austin, USA (e-mail: suzannah.creech@va.gov).

Funding This work was supported by Veterans Health Administration Health Services Research \& Development IIR13-81, and by the Veterans Health Administration VISN 17 Center of Excellence for 
Research on Returning War Veterans and the Central Texas Veterans Health Care System.

\section{Compliance with Ethical Standards:}

Conflict of Interest: The authors report no financial relationships with commercial interests. The views expressed in this article are those of the authors and do not necessarily reflect the position or policy of the Department of Veterans Affairs or the United States government.

\section{REFERENCES}

1. Dichter ME, Cerulli C, Bossarte RM. Intimate Partner Violence Victimization Among Women Veterans and Associated Heart Health Risks. Womenter ME, Cerulli . 2011;21(4):S190-S194. https://doi.org/ 10.1016/j.whi.2011.04.008

2. Dichter ME, Haywood TN, Butler AE, Bellamy SL, Iverson KM. Intimate Partner Violence Screening in the Veterans Health Administration: Demographic and Military Service Characteristics. Am J Prev Med 2017;52(6):761-768. https://doi.org/10.1016/j.Amepre.2017.01.003

3. Kimerling R, Iverson KM, Dichter ME, Rodriguez AL, Wong A, Pavao J. Prevalence of Intimate Partner Violence among Women Veterans who Utilize Veterans Health Administration Primary Care. J Gen Intern Med 2016;31(8):888-894. https://doi.org/10.1007/s11606-016-3701-7

4. Frayne SM, Phibbs CS, Saechao F, et al. Sourcebook: Women Veterans in the Veterans Health Administration. Volume 4: Longitudinal Trends in Sociodemographics, Utilization, Health Profile, and Geographic Distribu tion. Womenbook: Women Veterans in the Veterans Health Administration. Volume 4: Longitudinal Trends in Sociodemographics, Utilization, $\mathrm{He}$

5. Martin SL, Harris-Britt A, Li Y, Moracco KE, Kupper LL, Campbell JC. Changes in Intimate Partner Violence During Pregnancy. J Fam Violence 2004;19(4):201-210. https://doi.org/10.1023/B:JOFV.0000032630. 50593.93

6. Taillieu TL, Brownridge DA. Violence against pregnant women: Prevalence, patterns, risk factors, theories, and directions for future research. Aggress Violent Behav 2010;15(1):14-35. https://doi.org/10.1016/j.avb. 2009.07.013

7. Sadler AG, Mengeling MA, Fraley SS, Torner JC, Booth BM. Correlates of Sexual Functioning in Women Veterans: Mental Health, Gynecologic Health, Health Status, and Sexual Assault History. Int J Sex Health 2012;24(1):60-77. https://doi.org/10.1080/19317611.2011.640388

8. Wilson LC. The Prevalence of Military Sexual Trauma: A Meta-Analysis. Trauma Violence Abuse 2018;19(5):584-597. https://doi.org/10.1177/ 1524838016683459

9. Lehavot K, Hoerster KD, Nelson KM, Jakupcak M, Simpson TL. Health Indicators for Military, Veteran, and Civilian Women. Am J Prev Med 2012;42(5):473-480. https://doi.org/10.1016/j.amepre.2012.01. 006

10. Gerber MR, Iverson KM, Dichter ME, Klap R, Latta RE. Women Veterans and Intimate Partner Violence: Current State of Knowledge and Future Directions. J Womenson KM, D 2014;23(4):302-309. https://doi. org/10.1089/jwh.2013.4513

11. Halim N, Beard J, Mesic A, Patel A, Henderson D, Hibberd P. Intimate partner violence during pregnancy and perinatal mental disorders in low and lower middle income countries: A systematic review of literature, 19901990 th. Clin Psychol Rev 2018;66:117-135. https://doi.org/10. 1016/j.cpr.2017.11.004

12. Sharps PW, Laughon K, Giangrande SK. Intimate Partner Violence and the Childbearing Year: Maternal and Infant Health Consequences. Trauma Violence Abuse 2007;8(2):105-116. https://doi.org/10.1177/ 1524838007302594

13. Alhusen JL, Ray E, Sharps P, Bullock L. Intimate Partner Violence During Pregnancy: Maternal and Neonatal Outcomes. J Women E, Sharp 2015;24(1):100-106. https://doi.org/10.1089/jwh.2014.4872

14. Beydoun HA, Beydoun MA, Kaufman JS, Lo B, Zonderman AB. Intimate partner violence against adult women and its association with major depressive disorder, depressive symptoms and postpartum depression: A systematic review and meta-analysis. Soc Sci Med 2012;75(6):959-975. https://doi.org/10.1016/j.socscimed.2012.04.025

15. Creech S, Davis K, Howard M, Pearlstein T, Zlotnick C. Psychological/ verbal abuse and utilization of mental health care in perinatal women seeking treatment for depression. Arch WomenK, Howard M, Pea 2012;15(5):361-365. https://doi.org/10.1007/s00737-012-0294-y

16. Johnson DM, Zlotnick C. Utilization of Mental Health Treatment and Other Services by Battered Women in Shelters. Psychiatr Serv 2007;58(12): 1595-1597. https://doi.org/10.1176/ps.2007.58.12.1595

17. Dichter ME, Sorrentino AE, Haywood TN, et al. Women's Healthcare Utilization Following Routine Screening for Past-Year Intimate Partner Violence in the Veterans Health Administration. J Gen Intern Med 2018;33(6):936-941. https://doi.org/10.1007/s11606-018-4321-1

18. Mattocks KM, Kroll-Desrosiers A, Kinney R, Singer S. Understanding Maternity Care Coordination for Women Veterans Using an Integrated Care Model Approach. J Gen Intern Med 2019;34(1):50-57. https://doi. org/10.1007/s11606-019-04974-Z

19. Petterson S, McNellis R, Klink K, Meyers D, Bazemore A. The State of Primary Care in the United States: A Chartbook of Facts and Statistics. Robert Graham Center; 2018. https://www.graham-center.org/content/ $\mathrm{d}$ am/rgc/document s/publications-reports/reports / PrimaryCareChartbook.pdf

20. Gross GM, Kroll-Desrosiers A, Mattocks K. A Longitudinal Investigation of Military Sexual Trauma and Perinatal Depression. J Women-Desrosie 2020;29(1):38-45. https://doi.org/10.1089/jwh.2018.7628

21. Kroll-Desrosiers AR, Crawford SL, Moore Simas TA, Clark MA, Bastian LA, Mattocks KM. Rates and Correlates of Depression Symptoms in a Sample of Pregnant Veterans Receiving Veterans Health Administration Care. Womenl-Desrosiers AR 2019;29(4):333-340. https://doi.org/10.1016/j.whi.2019.04.008

22. Kroll-Desrosiers AR, Crawford SL, Moore Simas TA, Clark MA, Mattocks KM. Treatment and Management of Depression Symptoms in Pregnant Veterans: Varying Experiences of Mental Health Care in the Prenatal Period. Psychiatr Q. Published online February 1, 2020. https://doi.org/10.1007/s11126-019-09676-7

23. Mattocks KM, Baldor R, Bean-Mayberry B, et al. Factors Impacting Perceived Access to Early Prenatal Care among Pregnant Veterans Enrolled in the Department of Veterans Affairs. Womenocks KM, Baldor 2019;29(1):56-63. https://doi.org/10.1016/j.whi.2018.10.001

24. Chan C, Chan Y, Au A, Cheung G. Reliability and Validity of the "Extended - Hurt, Insult, Threaten, Scream" (E-Hits) Screening Tool in Detecting Intimate Partner Violence in Hospital Emergency Departments in Hong Kong. Hong Kong J Emerg Med 2010;17(2):109-117. https://doi. org/10.1177/102490791001700202

25. Iverson KM, King $\mathbf{M W}$, Gerber $\mathbf{M R}$, et al. Accuracy of an Intimate Partner Violence Screening Tool for Female VHA Patients: A Replication and Extension: IPV Screening Tool for Female Veterans. J Trauma Stress 2015;28(1):79-82. https://doi.org/10.1002/jts.21985

26. Kimerling R, Gima K, Smith MW, Street A, Frayne S. The Veterans Health Administration and Military Sexual Trauma. Am J Public Health 2007;97(12):2160-2166. https://doi.org/10.2105/AJPH.2006.092999

27. Bergink V, Kooistra L, Lambregtse-van den Berg MP, et al. Validation of the Edinburgh Depression Scale during pregnancy. J Psychosom Res 2011;70(4):385-389. https://doi.org/10.1016/j.Jpsychores.2010.07.008

28. Fried DA, Helmer D, Halperin WE, Passannante M, Holland BK. Health and Health Care Service Utilization Among U.S. Veterans Denied VA Service-Connected Disability Compensation: A Review of the Literature. Mil Med 2015;180(10):1034-1040. https://doi.org/10.7205/ MILMED-D-14-00435

29. Veterans Health Administration. VHA DIRECTIVE 1198: INTIMATE PARTNER VIOLENCE ASSISTANCE PROGRAM. Department of Veterans Affairs; 2019:1-11. Accessed February 25, 2020. https://www.va.gov/ vhapublications/ViewPublication.asp?pub_ID $=8192$

30. Bair-Merritt MH. Lewis-Ois-Oirs; 2019:1-11. Accessed February 25, 2020. https://www.va.gov/vhapublications/ViewPubAmerican J Prev Med. 2014;46(2):188-194. https://doi.org/10.1016/j.Amepre.2013.10. 001

31. Yonkers KA, Smith MV, Forray A, et al. Pregnant Women With Posttraumatic Stress Disorder and Risk of Preterm Birth. JAMA Psychiatry 2014;71(8):897. https://doi.org/10.1001/jamapsychiatry.2014.558

32. Rogal SS, Poschman $\mathbf{K}$, Belanger $\mathbf{K}$, et al. Effects of posttraumatic stress disorder on pregnancy outcomes. J Affect Disord 2007;102(13):137-143. https://doi.org/10.1016/j.jad.2007.01.003

33. Onoye JM, Goebert D, Morland L, Matsu C, Wright T. PTSD and postpartum mental health in a sample of Caucasian, Asian, and Pacific Islander women. Arch Womens Ment Health 2009;12(6):393-400. https://doi.org/10.1007/s00737-009-0087-0

34. Viteri O, Soto E, Bahado-Singh R, Christensen C, Chauhan S, Sibai B. Fetal Anomalies and Long-Term Effects Associated with Substance Abuse 
in Pregnancy: A Literature Review. Amer J Perinatol 2014;32(05):405416. https://doi.org/10.1055/s-0034-1393932

35. Grekin R, O'Hara MW. Prevalence and risk factors of postpartum posttraumatic stress disorder: A meta-analysis. Clin Psychol Rev 2014;34(5):389-401. https://doi.org/10.1016/j.cpr.2014.05.003

36. Bosquet Enlow M, Kitts RL, Blood E, Bizarro A, Hofmeister M, Wright RJ. Maternal posttraumatic stress symptoms and infant emotional reactivity and emotion regulation. Infant Behav Dev 2011;34(4):487503. https://doi.org/10.1016/j.infbeh.2011.07.007

37. Harpaz-Rotem I, Rosenheck RA, Desai R. Assessing the Effects of Maternal Symptoms and Homelessness on the Mental Health Problems in their Children. Child Adolesc Mental Health 2009;14(4):168-174. https://doi.org/10.1111/j.1475-3588.2008.00519.x

38. Liu K, Ruggero CJ, Goldstein B, et al. Elevated cortisol in healthy female adolescent offspring of mothers with posttraumatic stress disorder. J Anxiety Disord 2016;40:37-43. https://doi.org/10.1016/j.janxdis 2016.04.003

39. Seng JS, Sperlich M, Low LK, Ronis DL, Muzik M, Liberzon I. Childhood Abuse History, Posttraumatic Stress Disorder, Postpartum Mental Health, and Bonding: A Prospective Cohort Study. J Midwifery
Women, Ronis D 2013;58(1):57-68. https://doi.org/10.1111/j.15422011.2012.00237.x

40. Sperlich M, Seng J, Rowe H, Fisher J, Cuthbert C, Taylor J. A CyclesBreaking Framework to Disrupt Intergenerational Patterns of Maltreatment and Vulnerability During the Childbearing Year. J Obstet Gynecol Neonatal Nurs 2017;46(3):378-389. https://doi.org/10.1016/j.jogn. 2016.11.017

41. Mattocks KM, Frayne S, Phibbs CS, et al. Five-year Trends in Women Veteransransramework to Disrupt Intergenerational PWomenocks KM, Frayne. 2014;24(1):e37-e42. https://doi.org/10.1016/j.whi.2013.10.002

42. Bagwell-Gray ME, Messing JT, Baldwin-White A. Intimate Partner Sexual Violence: A Review of Terms, Definitions, and Prevalence. Trauma Violence Abuse 2015;16(3):316-335. https://doi.org/10.1177/ 1524838014557290

Publisher's Note: Springer Nature remains neutral with regard to jurisdictional claims in published maps and institutional affiliations. 